\title{
Domestic Guests' Perception of Hotel Capacity Management Practices
}

\author{
*Abuelkassem A. A. Mohammad \\ *Lecturer at Hotel Management Department, Faculty of Tourism and Hotels, Minia \\ University, Minia, Egypt
}

\begin{abstract}
In their pursuit of achieving optimal revenues of room capacity, hotels adopt several capacity management practices that can negatively impact guest satisfaction and long-term loyalty. This study aimed to investigate the viewpoint of Egyptian domestic tourists about the practices of room capacity management undertaken by hotels in Egypt. The study focused on four major sets of practices with a total of 18 practices to be examined. A quantitative approach was adopted in this study using questionnaire survey as an instrument for collecting primary data. The sample of this study included 339 participants who were selected using snowball sampling technique to participate in the survey study of this research. The results revealed that all the 18 examined capacity management practices were found to be moderately unacceptable by participants with some significant association between the acceptance of these practices and participants' demographic characteristics and accommodation patterns. The results also showed that the investigated practices were perceived by participants to have a significant negative impact on their both overall satisfaction with hotels and loyalty. The study has also provided some practical recommendations to help hotel managers to avert the negative impacts of these practices on domestic guests' satisfaction and loyalty.
\end{abstract}

Keywords: capacity management, guest perception, satisfaction, loyalty.

\section{Introduction}

Capacity management refers to the ability and skill of an organization to balance between supply and demand through influencing demand or providing suitable capacity that meets demand. In other words, it is the process of matching customer demand for certain services and the ability of a service provider to satisfy this demand (Armistead \& Clark, 1993; Edgar, 1997). Edgar (1997) further explained that hotel capacity management is a strategy used for maximizing revenues of the hotel main services. Pullman and Rodgers (2010) differentiated between demand management and capacity management. Demand management concerns with directing the time and volume of demand for a service, while capacity management concerns with providing adequate capacity that satisfies demand. Nevertheless, capacity management is used as an overarching concept that involves managing both demand and capacity (Pullman \& Rodgers, 2010). In this context, a wide range of practices can be adopted by hotels to manage room capacity, such as: demand forecasting; market segmentation; pricing; inventory control policies; managing distribution channels; overbooking and cancellation policies (Tse, \& Poon, 2011). 
In a broad sense, practices of managing hotel room capacity are based on the price-occupancy mix which involves two main variables; i.e. average room rate and occupancy rate (Albert \& Augustina, 2015)

The strong competition the hotel market nowadays has forced many hotels to adopt aggressive strategies and practices for managing room capacity and maximizing revenues (Albert \& Augustina, 2015). However, some of these practices, such as: charging different prices for the same room; setting minimum length of stay; selecting certain guest segments, can negatively impact guest satisfaction and loyalty and ultimately the financial success of a hotel (Wirtz et al., 2003). In addition, many hotels in Egypt are targeting domestic tourists to compensate for the decline in the international tourists arrivals since 2011 to date. The majority of domestic tourists are considered to be price-sensitive (Pierret, 2011; Forbes et al., 2014; Jerenashvili, 2014). Therefore, they are more likely to be unsatisfied with capacity management practices, mainly price-related practices. Also, misunderstanding of capacity management practices by hotel guests could result in dissatisfaction (Sanghavi, 2005). This created a need for investigating the perception of domestic tourists about these practices and their impact on guest satisfaction and loyalty.

Furthermore, most of academic studies have focused on the implementation of capacity management strategies and practices rather than investigating guests' perceptions of these strategies/practices (Bolton et al., 2003; Kimes, 2003; Wirtz et al. 2003; Wang \& Bowie, 2009). Williams (1999) argued that more research is required to explore when, where and how capacity management practices can be adopted. Bolton et al. (2003) suggested that more studies are needed to examine the customer acceptance of capacity management practices, particularly price discrimination. Kimes (2003) recommended studying guest perception and reaction to accommodation restriction imposed by hotels. Also, Wirtz et al. (2003) proposed investigating the way hotel guests perceive capacity and revenue management strategies. Therefore, this study sets out to fill this gap in knowledge.

This study aims to explore domestic guests' perception, specifically perceived acceptance and fairness, of room capacity management practices undertaken by hotels in Egypt focusing mainly on four sets of practices: reservation practices; room pricing practices; accommodation restrictions practices; guest segmentation and displacement practices. It also aims to identify the impact of adopting these practices on domestic guests' satisfaction and loyalty, as well as to provide some practical implications that would enhance room capacity management in hotels without jeopardizing domestic guests' satisfaction and loyalty.

\section{Literature review}

\subsection{Capacity management in hotels}

Capacity management represents a challenging aspect of hotel management. First, the process of matching room demand with available rooms is a significant activity in hotels as room capacity is fixed and the financial success 
of the hotel is directly related to the utilization of available capacity (Armistead \& Clark, 1993; Klassen \& Rohleder, 2001; Albert \& Augustina, 2015). Second, in order to handle the constrained capacity of hotel rooms and optimize maximum revenues, hotel managers need to balance between occupancy rate and average room rates (Albert \& Augustina, 2015). Third, the perishable capacity of hotel rooms and fluctuated demand for accommodation are serious challenges for capacity management in hotels (Oh \& Pizam, 2008; Albert \& Augustina, 2015).

\subsection{Capacity management practices}

A number of strategies, techniques and practices can be used for managing hotel room capacity. This study focuses on four major sets of practices that are directly involved with hotel guests and might affect their perception, satisfaction and loyalty.

\subsubsection{Reservation practices}

Overbooking is a common practice among hotels nowadays, particularly hotels that adopt yield management (Wirtz et al., 2003; Pan, 2007; Tse \& Poon, 2011). Overbooking is the process of accepting reservations that surpass available room capacity to compensate for cancelations, no-shows and early departures and to provide a wide range of potential guests to select the most profitable ones (Baker et al., 2000; Wirtz et al. 2003; Gökşen, 2011). However, overbooking can be unsatisfactory when a guest arrives at the hotel for an overbooked room. Thus, hotels need to have a policy for handling these situations, such as providing compensation for guests (Gökşen, 2011).

Setting booking limits is another common reservation practice in hotels. It is the activity of determining the number of rooms to be sold at reduced rates in order to reserve some room capacity for later guests who are willing to pay higher rates (Pinder, 2005; Wilson et al., 2006). Another common reservation practice involves applying cancellation policy that addresses cancellation and change restrictions or penalties (Wirtz et al. 2003; Pan, 2007; Tse, \& Poon, 2011). Such a policy may include practices such as: charging guests a certain percentage of reservation deposit as a penalty for cancellation or change; implementing a non-refundable or non-change reservation policy; permitting reservation changes for certain room rates or dates (Kimes, 1994; Kimes \& Anderson, 2009; Gökşen, 2011). Some hotels set reservation restrictions, such as booking rooms in specific time before arriving or booking rooms for particular nights only (Kimes, 1994)

\subsubsection{Room pricing practices}

Room pricing practices are the most important practices of capacity management (Pan, 2007; Tse, \& Poon, 2011) because of their potential impact on guest satisfaction and loyalty (Pinder, 2005; Richard, 2013; Virvilaite et al., 2009). As a result, hotel managers need to explore the impact of these practices on guest satisfaction and loyalty in order to ensure a successful business in the competitive market of the hotel industry (Virvilaite et al., 2009). 
Also, the financial success of a hotel business mainly depends on its efficiency of managing room capacity and the rates charged for different rooms (Albert \& Augustina, 2015). Demand-based pricing is a common practice in hotels. It involves setting room rates according to forecasted demand volume (Kimes, 2003; Kimes \& Wirtz, 2003; Cross et al., 2009). During peak seasons, demand tends to be high and therefore hotels charge high prices/rates for rooms; while at off-season periods, demand declines and hotels offer reduced rates to attract more guests (Lee et al., 2008; Cross et al., 2009; Richard, 2013). In other words, price-sensitive guests can only afford to stay at hotels during off-seasons. Thus, many guests perceived this practice to be unfair (Kimes \& Wirtz, 2003).

Changing room rates according to time of reservation is another common pricing practice. This includes offering discounts for early reservations (Kimes, 2003; Kimes \& Wirtz, 2003; Gökşen, 2011) and setting higher rates for last-minute and urgent bookings (Wirtz et al., 2003). Price discrimination is also another common practice, where hotels set different prices/rates for essentially the same accommodation but to different guest segments (Pinder, 2005; Sanghavi, 2005; Tranter et al., 2008). Through offering multiple room rates to different segments, hotels can attract a wide range of guest segments and charge each segment the maximum price they are willing to pay which eventually achieves optimal revenues (Gökşen, 2011).

Hotels also set varied prices for same rooms through different distribution channels (Kimes, 2003; Tse, \& Poon, 2011), such as offering reduced rates only through hotel website reservations (Albert \& Augustina, 2015). Another pricing practice includes setting restrictions or fences for certain room rates, such as length of stay or change conditions (Cross et al., 2009; Kimes \& Anderson, 2009).

\subsubsection{Accommodation restrictions}

Hotels also impose some accommodation-related restrictions, also known as inventory control (Wirtz et al., 2003). Setting certain length of stay is a standard accommodation restriction in hotels according to which guests are obligated to stay at the hotel for a minimum number of nights, e.g. three-night minimum length of stay (Kimes, 1994; Wirtz et al., 2003). Some hotels associate this restriction with reduced rates or specific type of guests, such as transient (Kimes, 1994; 2003). Another inventory control restriction involves charging fees for early departure or offering only certain plans of accommodation (Wirtz et al., 2003).

\subsubsection{Guest segmentation and displacement}

The main purpose of capacity management practices is to achieve optimal mix of business through providing the right room capacity to the right guest at the right time and price (Kimes \& Wirtz, 2003). Guest segmentation helps hotels to identify and select guests who are willing to pay the highest price for their services which eventually maximize revenues (Gökşen, 2011). Thus, hotel managers can best utilize fixed capacity through classifying demand into market segments and select the segments that value their hotel services (Albert \& Augustina, 2015). 
Guest displacement is also a common hotel practice which involves categorizing guests into segments and replaces one segment/guest for another to select the optimal segment/guest (Tranter et al., 2009; Morse \& Beckman, 2016). In other words, when selecting segments/guests, hotels give priority to the most profitable segments/guests over other segments (Gökşen, 2011). For example, hotels tend to choose price-insensitive over price-sensitive guests (Pinder, 2005) and business guests over leisure guests (Sanghavi, 2005). Also, amongst different hotel guests and segments, certain guests are selected first, including: double occupants; longer-stay guests; large travel parties (Albert \& Augustina, 2015).

\subsection{Guest perception of capacity management practices}

Reviewing the relevant literature revealed that a number of capacity management practices can adversely affect guests' perceptions, satisfaction and loyalty. For example, pricing practices such as charging different prices for same service or demand-based pricing are perceived by many guests as financial risks and unfair transactions (Kimes, 1994; Wirtz et al., 2003). Setting extensive restrictions for a slight rate reduction is also perceived as unfair transaction (Kimes, 1994); where fairness of a transactions is the extent to which a guest accepts a transaction and considers it to be reasonable and worth its costs (Bolton et al., 2003). Also, practices such as: restricting availability to certain rates; restricting capacity to preferred guests; accepting bookings that exceeding hotel available capacity, negatively affects guests' satisfaction as they consider these practices to be unsatisfactory and unfair (Wirtz et al., 2003). Manipulation of room rates has also a significant impact on customer's satisfaction and loyalty as guest associate prices with the value and quality of services (Malik et al., 2012). In addition, lack of understanding by hotel guests of capacity management practices results in confusions and conflicts that can negatively impact on guest satisfaction and loyalty and ultimately endanger the hotel long-term success (Wirtz et al., 2003; Sanghavi, 2005).

Despite the importance of capacity management practices in achieving optimal revenues, it is also crucial for hotel managers to consider guest perception of these practices and their potential negative impacts on guest satisfaction and loyalty to ensure a competitive and successful hotel business (Virvilaite et al., 2009). On one hand, positive guest perception and satisfaction is highly associated with guest loyalty (Bowen \& Chen, 2001). Also, satisfactory practices and services results in satisfied and loyal guests with higher tendency to be repeat guests and to refer hotels to other guests (Malik et al., 2012). Furthermore, the extent to which room capacity matches demand has a direct effect on guest satisfaction, hotel profitability, and future market position of a hotel (Pullman \& Rodgers 2010). On the other hand, negative perception of hotel practices or services leads to unsatisfied guests which eventually results in losing hotel future revenues and endanger hotel's long-term success (Sanghavi, 2005). Also, the cost of attracting new guests is much more than retaining current guests (Richard, 2013). 


\section{Research methodology}

This study has adopted a quantitative approach and used questionnaire survey as an instrument for gathering primary data. The questionnaire form included five sections. Section one aimed to explore the demographic characteristics and accommodation patterns of the participants through four questions about demographics and four questions about accommodation with a total of eight questions. Section two aimed to explore domestic guest acceptance of four main sets of capacity management practices with a total of 18 practices on a five-degree Likert scale, where: $1=$ completely acceptable; $2=$ acceptable; $3=$ neutral; $4=$ unacceptable; $5=$ completely unacceptable. Section three investigated the negative impacts of the examined capacity management practices on guest satisfaction and loyalty through three Likert scale questions, where 1 is "completely unsatisfied" and 5 is "completely satisfied". Section four aimed to ascertain how hotels can avert the negative impacts of capacity management practices through one question. Section five aimed to gather any further comments and suggestions that participants might have made about the investigated issue.

The validity of the research instrument was assured through adopting a peer review technique, as proposed by Creswell (2009), which included reviewing the questionnaire form by a panel of four academic scholars in the field of hospitality management who confirmed the instrument validity. Further procedures were also undertaken to guarantee the validity of the research results, including: using closed-ended questions which are easier to understand and complete; discussing questions to all participants explicitly; providing adequate time for participants to fill in the questionnaire; all returned questionnaire forms were double checked; using SPSS for analyzing gathered data to produce accurate results. The reliability of the questionnaire form was confirmed through conducting a Cronbach's alpha test as suggested by Pallant (2005). The results showed that the instrument was reliable and yielded an overall score of 0.802 .

The population of this study included domestic tourists in Egypt who have stayed in hotels at least once. There are no official reports or statistics about the number of domestic tourists in Egypt, but it was approximated to be about 21 million in 2016 (Colliers International, 2015). The sample of this study included 339 participants. A snowball sampling technique was adopted to access the participants of this study. The sample has initially started by few participants who fitted the sampling characteristics (local nationals who stayed in hotels at least once) and they recruited more eligible participants through their social network. The sample represented only four geographic regions in Egypt for accessibility reasons (i.e. Minia; Luxor; Aswan; Cairo); as well as it represented different demographic segments of domestic tourists (Table 1).

The questionnaire survey was self-administrated and distributed amongst the target participants. A total of 339 questionnaire forms were returned and valid for analysis with an approximate response rate of $85 \%$. 
The returned questionnaire forms were checked for validity, coded and entered into SPSS for analysis. Descriptive statistics, including: frequencies; percentage; mean; standard deviation; rank, were generated to conclude the brief features of the gathered data. Chi square test of association was also performed to explore any relationships between the examined capacity management practices and the demographic characteristics and accommodation patterns of the participants.

\section{Results and discussion}

\subsection{Demographics and accommodation patterns}

This section aimed to explore the demographic characteristics and accommodation patterns of the participants, through eight questions, in order to explore any association between these patterns and the perception of capacity management practices. The first four questions aimed to explore the demographic characteristics of the participants; focusing mainly on age, monthly income, marital status and occupation. The results (see Table 1) showed that the majority of the participants were either between 25 to 34 years old $(48.7 \%)$ or less than 25 years old $(31 \%)$ while the remaining percentages were either between 35 to 50 or more than 50 years old. With regard to the monthly income, the largest percentage of the participants (44.2\%) had monthly income between 2500 to less than 5000 L.E followed by $33.6 \%$ of the participants earning less than 2500 L.E monthly and $13.3 \%$ earned between 5000 to 7500 L.E while only $8.8 \%$ had a monthly income more than 7500 L.E. When it comes to the marital status, the largest proportion of the participants $(58.1 \%)$ were single compared with $33.4 \%$ of the participants who were married. The results also showed that $44.3 \%$ of the participants were employed and $38.9 \%$ owned their own business while $16.8 \%$ had other occupational status (retired, military, etc.).

Table 1: Demographic characteristics of the participants $(n=339)$

\begin{tabular}{|lcclcc|}
\hline Age & Freq. & $\mathbf{\%}$ & Monthly income & Freq. & \% \\
\hline Less than 25 years & 105 & 31.0 & Less than 2500 L.E & 114 & 33.6 \\
\hline From 25 to 34 years & 165 & 48.7 & $\begin{array}{l}\text { From 2500 to less than 5000 } \\
\text { L.E }\end{array}$ & 150 & 44.2 \\
\hline From 35 to 50 years & 63 & 18.6 & $\begin{array}{l}\text { From 5000 to less than 7500 } \\
\text { L.E }\end{array}$ & 45 & 13.3 \\
\hline More than 50 years & 6 & 1.8 & More than 7500 L.E & 30 & 8.8 \\
\hline Total & $\mathbf{3 3 9}$ & $\mathbf{1 0 0}$ & Total & $\mathbf{3 3 9}$ & $\mathbf{1 0 0}$ \\
\hline Marital status & Freq. & $\mathbf{\%}$ & Occupation & Freq. & $\mathbf{\%}$ \\
\hline Single & 197 & 58.1 & Employed & 150 & 44.3 \\
\hline Married & 113 & 33.4 & Entrepreneur & 132 & 38.9 \\
\hline Others & 29 & 8.5 & Others & 57 & 16.8 \\
\hline Total & $\mathbf{3 3 9}$ & $\mathbf{1 0 0}$ & Total & $\mathbf{3 3 9}$ & $\mathbf{1 0 0}$ \\
\hline
\end{tabular}

The other four questions aimed to identify the accommodation patterns of the participants. Participants were asked if they have stayed in hotels before. The results (Table 2) showed that all the 339 participants considered in this study have stayed in hotels in Egypt at least once. Participants who did not stay in hotels were excluded to guarantee the collection of reliable and accurate data. 
Respondents were also asked about the type of hotels they have stayed in. The results revealed that the largest percentage of the respondents $(42.5 \%)$ have stayed in five-star hotels followed by approximately $21 \%$ of the participants stayed in three-star hotels while only $19.5 \%$ have stayed in four-star hotels and about $16 \%$ stayed in hotels less than three stars.

Participants were asked about the purposes of their visits and hotel accommodation. As shown in Table 2, more than half of the participants (approximately 55\%) have stayed in hotels for leisure purposes while $23 \%$ stayed in hotels for business purposes. Roughly $17 \%$ of the respondents stayed in hotels to attend conferences and only $5.3 \%$ of the respondents have stayed in hotels for other purposes.

Respondents were also asked about the regularity of their accommodation in hotels. The results showed that about $47 \%$ of the respondents have stayed in hotels at least once a year followed by $27.5 \%$ of the participants stayed in hotels more than three times annually. Approximately $17 \%$ of the respondents have stayed in hotels twice a year and only about $9 \%$ of the participants stayed in hotels three times per year.

Table 2: Accommodation patterns of the participants

\begin{tabular}{|c|c|c|c|c|c|}
\hline Preferred type of hotel & Freq. & $\%$ & Stayed in hotels & Freq. & $\%$ \\
\hline Five-star hotels & 144 & 42.5 & Yes & 339 & 100 \\
\hline Four-star hotels & 66 & 19.5 & No & 0 & 0 \\
\hline Three-star hotels & 72 & 21.2 & - & - & - \\
\hline Less than three stars & 57 & 16.8 & - & - & - \\
\hline Total & 339 & 100 & Total & 339 & 100 \\
\hline Regularity of accommodation & Freq. & $\%$ & $\begin{array}{l}\text { Purpose of } \\
\text { accommodation }\end{array}$ & Freq. & $\%$ \\
\hline Once a year & 159 & 46.9 & Leisure & 186 & 54.9 \\
\hline Twice a year & 57 & 16.8 & Business & 78 & 23.0 \\
\hline Three times a year & 30 & 8.8 & Conference & 57 & 16.8 \\
\hline More than three times a year & 93 & 27.5 & Others & 18 & 5.3 \\
\hline Total & 339 & 100 & Total & 339 & 100 \\
\hline
\end{tabular}

In general, it can be inferred that all participants have stayed in hotels at least once and most of them have stayed mostly in five-star and four star-star hotels mainly for leisure and recreational purposes.

\subsection{Acceptance of capacity management practices}

This section aimed to explore domestic tourists' acceptance of hotel capacity management practices focusing on four major sets of practices: room reservation practices; room pricing practices; accommodation restrictions; guest segmentation and displacement.

\subsubsection{Acceptance of room reservation practices}

The results (Table 3) showed that there were three reservation practices, i.e." requiring room reservation beforehand";" requesting deposit to guarantee reservation"; "restricting time of reservation cancellation/change " were 
accepted by domestic tourists and scored a mean of acceptance below 2 and a significant variation in opinions with a standard deviation of approximately 1 . "Charging fees for reservation cancellation/change" was found to be slightly accepted with a mean score of 2.77 while "sharing rooms with other guests or transfer to other hotels" was considered to be slightly unacceptable practice and scored a mean of 3.97. Other practices, including: "changing room type or rate without notifying guests"; "unavailability of reserved room upon guest arrival", were found to be strongly unaccepted and scored a mean score greater than 4 .

Table 3: Domestic guest acceptance of room reservation practices

\begin{tabular}{|lrcc|}
\hline Acceptance of room reservation practices & Mean $*$ & SD** & Rank \\
\hline Requiring room reservation beforehand & 1.47 & 0.87 & 1 \\
\hline Requesting deposit to guarantee reservation & 1.75 & 1.00 & 2 \\
\hline Restricting time of reservation cancellation/change & 1.95 & 1.02 & 3 \\
\hline Charging fees for reservation cancellation/change & 2.77 & 1.29 & 4 \\
\hline Changing room type or rate without notifying guests & 4.05 & 1.12 & 6 \\
\hline Unavailability of reserved room upon guest arrival & 4.18 & 1.15 & 7 \\
\hline Sharing rooms with other guests or transfer to other hotels & 3.97 & 1.26 & 5 \\
\hline Overall mean of acceptance of reservation practices & & 2.87 & \\
\hline
\end{tabular}

*Mean of acceptance; where $1=$ completely acceptable; $2=$ acceptable; $3=$ neutral; $4=$ unacceptable; $5=$ completely unacceptable

$* * \mathrm{SD}=$ Standard deviation

A Chi square test was performed to explore any association between the demographic characteristic and accommodation patterns of the participants (marital status; monthly income; purpose of hotel stay; preferred hotel grade; frequency of hotel stay annually) and the acceptance of reservation practices. The results (Table 4) revealed that there were statistically-significant associations between participants' characteristics and the acceptance of reservation practices. Marital status of the participants, for instance, was significantly associated with some reservation practices, including: "requiring room reservation beforehand", $X^{2}(4, \mathrm{~N}=339)=21.23, p<0.05$; "requesting deposit to guarantee reservation", $X^{2}(4, \mathrm{~N}=339)=11.58, p<0.05$; "changing room type or rate without notifying guests", $X^{2}(4, \mathrm{~N}=339)=20.36, p<0.05$; "sharing rooms with other guests or transfer to other hotels", $X^{2}(4, \mathrm{~N}=339)=$ $17.28, p<0.05$. In other words, the extent to which participants accepted these reservation practices differ according to their marital status (being single, married or others). Similarly, other characteristics of the participants (i.e. income; stay purpose; hotel grade; stay frequency) were significantly associated with the acceptance of all reservation practices (Table 4). Participants' income was associated with "requiring room reservation beforehand", $X^{2}(12, \mathrm{~N}=339)=21.63, p<0.05$; indicating that the acceptance of this practice vary according to different segments of monthly income of the participants that were presented earlier in Table 1. 
Table 4: Association between participants' characteristics and acceptance of room reservation practices

\begin{tabular}{|c|c|c|c|c|c|c|c|c|c|c|}
\hline \multirow{3}{*}{ Room reservation practices } & \multicolumn{10}{|c|}{ Characteristics of the participants } \\
\hline & \multicolumn{2}{|c|}{ Marital Status } & \multicolumn{2}{|c|}{ Income } & \multicolumn{2}{|c|}{ Stay purpose } & \multicolumn{2}{|c|}{ Hotel grade } & \multicolumn{2}{|c|}{ Stay Freq. } \\
\hline & $X^{2}$ & Sig. & $X^{2}$ & Sig. & $X^{2}$ & Sig. & $X^{2}$ & Sig. & $X^{2}$ & Sig. \\
\hline Requiring room reservation beforehand & 21.23 & $0.00 *$ & 21.63 & $0.042 *$ & 94.49 & $0.00 *$ & 57.44 & $0.00 *$ & 60.64 & $0.00 *$ \\
\hline Requesting deposit to guarantee reservation & 11.58 & $0.021 *$ & 50.42 & $0.00 *$ & 66.09 & $0.00 *$ & 60.55 & $0.00^{*}$ & 51.48 & $0.00 *$ \\
\hline $\begin{array}{l}\text { Restricting time of reservation } \\
\text { cancellation/change }\end{array}$ & 2.98 & 0.56 & 27.50 & $0.007 *$ & 106.9 & $0.00 *$ & 33.09 & $0.001 *$ & 68.77 & $0.00^{*}$ \\
\hline Charging fees reservation cancellation/change & 4.00 & 0.405 & 20.47 & $0.059^{*}$ & 85.01 & $0.00^{*}$ & 30.40 & $0.002 *$ & 59.92 & $0.00 *$ \\
\hline $\begin{array}{l}\text { Changing room type or rate without notifying } \\
\text { guests }\end{array}$ & 20.36 & $0.00 *$ & 34.66 & $0.001 *$ & 45.99 & $0.00 *$ & 53.51 & $0.00 *$ & 52.57 & $0.00^{*}$ \\
\hline $\begin{array}{l}\text { Unavailability of reserved room upon guest } \\
\text { arrival }\end{array}$ & 9.23 & 0.055 & 19.35 & 0.080 & 52.49 & $0.00^{*}$ & 72.88 & $0.00 *$ & 61.35 & $0.00^{*}$ \\
\hline $\begin{array}{l}\text { Sharing rooms with other guests or transfer to } \\
\text { other hotels }\end{array}$ & 17.28 & $0.002 *$ & 24.18 & $0.019^{*}$ & 59.09 & $0.00 *$ & 87.34 & $0.00^{*}$ & 77.48 & $0.00^{*}$ \\
\hline
\end{tabular}

*Statistically-significant association, where $p<0.05$.

In a broad sense, the results showed that reservation practices related to making reservation, paying mandatory deposit and restricting reservation change/cancellation were accepted by participants; while practices related to changing reservation details by the hotel (date and room type or rate) were unacceptable. It can also be noticed that the degree of accepting these practices differ according to the various characteristics of the participants revealing that these practices can be accepted by domestic tourists with certain characteristics and rejected by others

\subsubsection{Acceptance of room pricing practices}

The results revealed that the majority of the investigated pricing practices were found to be slightly unacceptable by participants of domestic tourists and scored a mean of acceptance more than 3.5 with a moderate variation in participants' opinions where the standard deviation was around 1.3 (Table 5). 
Table 5: Domestic guest acceptance of room pricing practices

\begin{tabular}{|c|c|c|c|}
\hline Room pricing practices & Mean * & SD** & Rank \\
\hline Manipulating room rates according to guest type & 3.52 & 1.37 & 2 \\
\hline Setting rooms rates according to season/volume of room demand & 3.55 & 1.39 & 3 \\
\hline Charging different room rates according to time of reservation & 3.25 & 1.28 & 1 \\
\hline Requiring full payment of accommodation package beforehand & 3.59 & 1.13 & 4 \\
\hline Overall mean of acceptance of room pricing practices & \multicolumn{3}{|c|}{3.47} \\
\hline
\end{tabular}

*Mean of acceptance; where $1=$ completely acceptable; $2=$ acceptable; $3=$ neutral; $4=$ unacceptable; $5=$ completely unacceptable

$* * \mathrm{SD}=$ Standard deviation

Table 6: Association between participants' characteristics and acceptance of room pricing practices

\begin{tabular}{|c|c|c|c|c|c|c|c|c|c|c|}
\hline \multirow{3}{*}{ Room pricing practices } & \multicolumn{10}{|c|}{ Characteristics of the participants } \\
\hline & \multicolumn{2}{|c|}{ Marital Status } & \multicolumn{2}{|c|}{ Income } & \multicolumn{2}{|c|}{ Stay purpose } & \multicolumn{2}{|c|}{ Hotel grade } & \multicolumn{2}{|c|}{ Stay Freq. } \\
\hline & $X^{2}$ & Sig. & $X^{2}$ & Sig. & $X^{2}$ & Sig. & $X^{2}$ & Sig. & $X^{2}$ & Sig. \\
\hline $\begin{array}{l}\text { Manipulating room rates according to } \\
\text { guest type }\end{array}$ & 15.25 & $0.004 *$ & 41.86 & $0.00^{*}$ & 40.81 & $0.00^{*}$ & 40.18 & $0.00 *$ & 52.23 & $0.00^{*}$ \\
\hline $\begin{array}{l}\text { Setting rooms rates according to } \\
\text { season/volume of room demand }\end{array}$ & 19.98 & $0.001 *$ & 22.30 & $0.34 *$ & 38.21 & $0.00 *$ & 45.89 & $0.00 *$ & 42.30 & $0.00 *$ \\
\hline $\begin{array}{l}\text { Charging different room rates } \\
\text { according to time of reservation }\end{array}$ & 40.02 & $0.00 *$ & 53.81 & $0.00^{*}$ & 43.22 & $0.00^{*}$ & 86.46 & $0.00 *$ & 35.86 & $0.003^{*}$ \\
\hline $\begin{array}{l}\text { Requiring full payment of } \\
\text { accommodation package beforehand }\end{array}$ & 15.77 & $0.003^{*}$ & 37.01 & $0.00 *$ & 47.16 & $0.00 *$ & 37.64 & $0.00 *$ & 77.06 & $0.00^{*}$ \\
\hline
\end{tabular}

*Statistically-significant association, where $p<0.05$. 
The results of the Chi square test (see table 6) showed that there were statistically-significant association between every characteristic of the participants and all of the examined practices. For example, marital status of the participants was significantly associated with "manipulating room rates according to guest type", $X^{2}(4, \mathrm{~N}=339)=15.25, p<0.05$. In other words, the degree of participant acceptance of room rate manipulations varies according to the marital status of the participant (being single, married or others). Similarly, other characteristics including: monthly income; purpose of accommodation; preferred hotel grade; frequency of hotel accommodation, were found to be statistically significant with all examined practices of room pricing.

It can be concluded from these results that all the examined room pricing practices were moderately unacceptable by the majority of the participants. Interestingly, the extent of accepting or rejecting these practices was statistically associated with certain characteristics of the participants.

\subsubsection{Acceptance of accommodation restrictions}

As shown in Table 7, all of the examined accommodation restrictions were considered to be marginally unacceptable by approached domestic tourists. All four accommodation restrictions scored a mean score of acceptance around 3.5 on the five-degree scale indicating a tendency to disapproval of these practices with reasonable variation in participants' views where the standard deviation was about 1.27.

Table 7: Domestic guest acceptance of hotel accommodation restrictions

\begin{tabular}{|lccc|}
\hline Acceptance of accommodation restrictions & Mean $*$ & SD $^{* *}$ & Rank \\
\hline Setting a minimum length of stay & 3.58 & 1.43 & 3 \\
\hline $\begin{array}{l}\text { Offering only certain plans of accommodation (e.g. full } \\
\text { board) }\end{array}$ & 3.30 & 1.34 & 1 \\
\hline Rejecting any changes of accommodation plans/ packages & 3.54 & 1.27 & 2 \\
\hline Inflexibility of changing length of stay & 3.76 & 1.03 & 4 \\
\hline Overall mean of accepting accommodation restriction & & 3.54 & \\
\hline
\end{tabular}

*Mean of acceptance; where $1=$ completely acceptable; $2=$ acceptable; $3=$ neutral; $4=$ unacceptable; $5=$ completely unacceptable

$* * \mathrm{SD}=$ Standard deviation

The results of the Chi square test (Table 8) showed that there were statisticallysignificant associations between characteristics of the participants and acceptance of accommodation restrictions. For instance, the monthly income of the participants was significantly associated with: "setting a minimum length of stay", $X^{2}(12, \mathrm{~N}=339)=52.82, p<0.05$; "offering only certain plans of accommodation", $X^{2}(12, \mathrm{~N}=339)=20.36, p<0.05$. This means that the extent to which participants can accept the accommodation restrictions differ in accordance with their monthly income. Also, other characteristics of the participants (purpose of accommodation, marital status, favorite hotel grade, frequency of accommodation) were significantly associated with accepting the investigated accommodation restrictions, as shown in Table 8. 
Table 8: Association between participants' characteristics and acceptance of hotel accommodation restrictions

\begin{tabular}{|c|c|c|c|c|c|c|c|c|c|c|}
\hline \multirow{3}{*}{ Restriction practices } & \multicolumn{10}{|c|}{ Characteristics of the participants } \\
\hline & \multicolumn{2}{|c|}{ Marital Status } & \multicolumn{2}{|c|}{ Income } & \multicolumn{2}{|c|}{ Stay purpose } & \multicolumn{2}{|c|}{ Hotel grade } & \multicolumn{2}{|c|}{ Stay Freq. } \\
\hline & $X^{2}$ & Sig. & $X^{2}$ & Sig. & $X^{2}$ & Sig. & $X^{2}$ & Sig. & $X^{2}$ & Sig. \\
\hline Setting a minimum length of stay & 18.86 & $0.002 *$ & 52.82 & $0.00^{*}$ & 56.57 & $0.00 *$ & 8.26 & $0.00 *$ & 104.9 & $0.00 *$ \\
\hline $\begin{array}{l}\text { Offering only certain plans of } \\
\text { accommodation (e.g. full board) }\end{array}$ & 17.31 & $0.002 *$ & 20.36 & 0.060 & 30.64 & $0.002 *$ & 57.53 & $0.00^{*}$ & 56.75 & $0.00^{*}$ \\
\hline $\begin{array}{l}\text { Rejecting any changes of } \\
\text { accommodation plans/packages }\end{array}$ & 19.66 & $0.001 *$ & 39.40 & $0.00 *$ & 33.31 & $0.001 *$ & 72.05 & $0.00 *$ & 77.47 & $0.00^{*}$ \\
\hline Inflexibility of changing length of stay & 23.63 & $0.00 *$ & 47.18 & $0.00^{*}$ & 51.01 & $0.00 *$ & 42.64 & $0.00^{*}$ & 33.70 & $0.006^{*}$ \\
\hline
\end{tabular}

*Statistically-significant association, where $p<0.05$.

It can be concluded form these results that all examined accommodation practices were moderately unacceptable by participants of domestic tourists. There were a variation in the participants' opinions regarding the acceptance of the accommodation restrictions and such variation was associated with demographic characteristics and accommodation patterns. 


\subsubsection{Acceptance of guest segmentation and displacement}

The results (see Table 9) showed that these practices were reasonably unaccepted by participants with mean score of acceptance around 3.7 and mild variation in participants opinions with a standard deviation of approximately 1.18. "Other practices" were unacceptable with a mean of 4.00 and included a further practice added by participants, i.e. "restricting certain seasons for only international tourists".

Table 9: Domestic guest acceptance of guest segmentation and displacement

\begin{tabular}{|lccc|}
\hline Acceptance of guest segmentation and displacement & Mean * & SD** & Rank \\
\hline Dealing with only certain guest segments & 3.72 & 1.16 & 2 \\
\hline $\begin{array}{l}\text { Giving priority for reservations of certain guest } \\
\text { segments over other segments }\end{array}$ & 3.73 & 1.12 & 3 \\
\hline $\begin{array}{l}\text { Allocating a number of rooms for only certain guest } \\
\text { segments }\end{array}$ & 3.53 & 1.26 & 1 \\
\hline Other practices (please specify) & 4.00 & & 4 \\
\hline Overall mean of accepting segmentation/displacement & & 3.74 \\
\hline
\end{tabular}

*Mean of acceptance; where $1=$ completely acceptable; $2=$ acceptable; $3=$ neutral; $4=$ unacceptable; $5=$ completely unacceptable

$* * \mathrm{SD}=$ Standard deviation

The results of the Chi square test (Table 10) showed that there were statistically significant associations between all participants' characteristics and the acceptance of all examined guests segmentation/displacement. In other words, the extent to which participants of the domestic tourists can accept displacement practices, including: "dealing with only certain guest segments"; "giving priority for reservations of certain guest segments over other segments"; "allocating a number of rooms for only certain guest segments", has varied according to the demographic characteristics and accommodation patterns of the participants. Frequency of hotel accommodation had a statistically-significant association with: "dealing with only certain guest segments" ", $X^{2}(16, \mathrm{~N}=339)=48.18, p<0.05$; "giving priority for reservations of certain guest segments over other segments" ", $X^{2}(16, \mathrm{~N}=339)$ $=61.79, p<0.05$; "allocating a number of rooms for only certain guest segments", $X^{2}(16, \mathrm{~N}=339)=47.47, p<0.05$.

Generally, all the three examined practices of guest segmentation/displacement were slightly unacceptable by participants of domestic tourists. Also, the variation of the acceptance degree of these practices among participants indicated the impact of demographic characteristics (i.e. marital status and monthly income) and accommodation patterns (purpose of hotel accommodation, preferred hotel grade, frequency of annual hotel accommodation) of the participants on how far they can accept or reject these practices. 
Table 10: Association between participants' characteristics and acceptance of guest segmentation/displacement practices

\begin{tabular}{|c|c|c|c|c|c|c|c|c|c|c|}
\hline \multirow{3}{*}{ Guest segmentation practices } & \multicolumn{10}{|c|}{ Characteristics of the participants } \\
\hline & \multicolumn{2}{|c|}{ Marital Status } & \multicolumn{2}{|c|}{ Income } & \multicolumn{2}{|c|}{ Stay purpose } & \multicolumn{2}{|c|}{ Hotel grade } & \multicolumn{2}{|c|}{ Stay Freq. } \\
\hline & $X^{2}$ & Sig. & $X^{2}$ & Sig. & $X^{2}$ & Sig. & $X^{2}$ & Sig. & $X^{2}$ & Sig. \\
\hline $\begin{array}{l}\text { Dealing with only certain guest } \\
\text { segments }\end{array}$ & 34.08 & $0.00 *$ & 29.83 & $0.003 *$ & 61.37 & $0.00 *$ & 33.69 & $0.001 *$ & 48.18 & $0.00 *$ \\
\hline $\begin{array}{l}\text { Giving priority for reservations of } \\
\text { certain guest segments over other } \\
\text { segments }\end{array}$ & 53.88 & $0.00^{*}$ & 37.83 & $0.00 *$ & 42.80 & $0.00 *$ & 56.80 & $0.00 *$ & 61.79 & $0.00 *$ \\
\hline $\begin{array}{l}\text { Allocating a number of rooms for } \\
\text { only certain guest segments }\end{array}$ & 20.52 & $0.00^{*}$ & 39.51 & $0.00^{*}$ & 50.13 & $0.00 *$ & 62.14 & $0.00 *$ & 47.47 & $0.00 *$ \\
\hline
\end{tabular}

*Statistically-significant association, where $p<0.05$.

\subsection{Impact of capacity management practices on guest satisfaction and loyalty}

Participants were asked to indicate their level of satisfaction with the examined capacity management practices on a five-degree Likert scale. The results revealed that participants were slightly unsatisfied with these practices with an overall mean score of satisfaction of 2.90 and significant variation of participants' satisfaction degree with a standard deviation of 1.17.

Participants were also asked to indicate how negatively can the investigated capacity management practice impact on their overall satisfaction with the hotel in general on a five-degree scale, where 1 is "no impact at all" and 5 " strong negative impact". The results showed that the examined practices had a significant negative impact on respondents' overall satisfaction with the hotel and scored a mean score of 3.34 on the scale with a standard deviation of 1.02.

Participants were also asked to specify the extent to which the examined practices can negatively impact on their long-term loyalty to a hotel on a five-degree scale where 1 is "no impact at all" and 5 " strong negative impact". The results showed that participants perceived the examined practices to have a significant negative impact on their long-term loyalty to a hotel with a mean score of 3.62 and a slight variation in participants' options where the standard deviation was 0.84 . 
The results of the Chi square test (Table 11) revealed that there were statistically-significant associations between characteristics of the participants and the extent to which capacity management practices can negatively impact on customer satisfaction and loyalty to a hotel. For example, marital status of the participants was significantly associated with: "impact of capacity management practices on guest satisfaction with the hotel", $X^{2}(4, \mathrm{~N}=339)=38.51, p<0.05$; "impact of capacity management practices on guest loyalty to the hotel", $X^{2}(4, \mathrm{~N}=339)=21.23, p<0.05$. This indicates that the perceived degree that capacity management practices can negatively impact on guests' satisfaction and loyalty differ according to the marital status (being single, married, others) of the participants. Similarly, the perceived negative impact of these practices was associated with all demographic characteristics and accommodation patterns of the participants

Table 11: Association between participants' characteristics and satisfaction with capacity practices

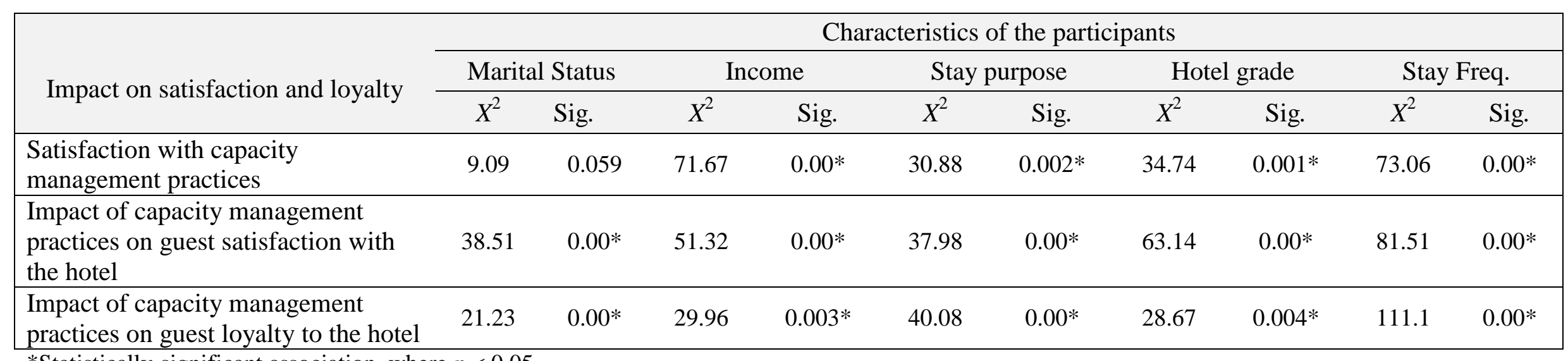

*Statistically-significant association, where $p<0.05$. 


\subsection{Handling the negative impacts of capacity management practices}

The results (see Table 12) showed that all the proposed procedures of handling the negative impacts of capacity management practices were agreed on by participants with an overall mean score of 1.75. "Monitoring the impact of these practices on guest satisfaction/loyalty on a regular basis" came at the first rank among the proposed practices and scored a mean of 1.54 with very limited variation in participants' views (standard deviation was 0.79). "Balancing between applying these practices and achieving guest satisfaction/loyalty" was ranked second among these practices and recorded a mean score of 1.66 followed by "applying these practices at a very limited scale" at the third rank and scored a mean of 1.82. At the fourth and last rank came "avoiding the implementation of these practices at all" and scored 2.01 as a mean score.

Table 12: Handling the negative impacts of capacity management practices

\begin{tabular}{|lccc|}
\hline Practices of preventing the negative impacts & Mean * & SD $^{* *}$ & Rank \\
\hline Avoiding the implementation of these practices at all & 2.01 & 1.18 & 4 \\
\hline Applying these practices at a very limited scale & 1.82 & 0.84 & 3 \\
\hline $\begin{array}{l}\text { Monitoring the impact of these practices on guest } \\
\text { satisfaction/loyalty on a regular basis }\end{array}$ & 1.54 & 0.79 & 1 \\
\hline $\begin{array}{l}\text { Balancing between applying these practices and } \\
\text { achieving guest satisfaction/loyalty }\end{array}$ & 1.66 & 0.98 & 2 \\
\hline Overall mean score & \multicolumn{3}{c}{1.75} \\
$\begin{array}{l}\text { *Mean of acceptance; where 1= strongly agree; } 2=\text { agree; } 3=\text { neutral; } \text { = disagree; 5= strongly disagree } \\
\text { **SD = Standard deviation }\end{array}$
\end{tabular}

\subsection{Further comments and suggestions}

Participants were asked if they have any further comments or suggestion to add about room capacity management practices and their impact on guest satisfaction and loyalty. Through analyzing the additional comments and suggestions, three main comments were concluded. First, a total of 17 participants (about 5\%) suggested that hotels need to treat their guests equally regardless if they are domestic or international and therefore local guests should not be deprived of the privileges provided for foreigners. Second, 14 participants $(4.1 \%)$ also proposed that hotels should provide adequate products and services for domestic tourist at reasonable prices. Third, 9 respondents (2.6\%) argued that hotels need to improve the quality of services and products provided for domestic tourists as these services were substandard particularly when compared with services provided for international tourists.

\section{Conclusions and recommendations}

This study has concluded some significant implications regarding domestic guest perception of capacity management practices and their impact on satisfaction and loyalty. The study examined domestic guest acceptance of 18 capacity management practices undertaken by hotels in Egypt and concluded that all the examined practices were unacceptable by domestic tourists. 
Thus, hotel managers need to reconsider undertaking these practices in an acceptable way to domestic tourists. The study also concluded that demographic characteristics of the participants (namely marital status and monthly income) and the accommodation patterns of the participants (i.e. purpose of hotel accommodation, preferred hotel grade, frequency of hotel accommodation) have a significant impact on domestic guest acceptance of the investigated practices. This indicates that domestic tourists with certain demographics and accommodation pattern may accept these practices more than others. Thus, hotels can explore and target certain segments of domestic tourists who can accept these practices. The study has also explored the perceived impact of capacity management practices on hotel guest satisfaction and long-term loyalty. It was concluded that these practices negatively impact guests' satisfaction and loyalty resulting in unsatisfied and infrequent guests which in its turn leads many hotels to lose a significant percentage of their domestic guests.

Based on the relevant literature and the results of the empirical investigation, some recommendations can be provided to help hotels manage their room capacity without threatening domestic guests' satisfaction and loyalty. Hoteliers are advised to serve and treat both domestic and international tourists equally through providing them with the same privileges, service and quality standards. Hotel managers are recommended to balance between achieving optimal revenues through the implementation of capacity management practices and satisfaction/loyalty of domestic tourists through regular checking of guests' feedback and impressions. Hotel managers are also advised to impose some accommodation restrictions/penalties (such as minimum length of stay) on reduced room rates only in order to make rack rates seem reasonable to guests. It is also worth recommending that capacity management practices should be adopted at a limited scale when it comes to dealing with domestic tourists as the majority of them perceive these practices to be unacceptable.

\section{Study limitations and opportunities for future research}

The relatively small size of the sample represented the main limitation of this study. The researcher was challenged by serious barriers during primary data collection, such as: accessibility difficulties; limited cooperation/responsiveness of the participants, which have resulted in a relatively small sample size that represented four cities. Thus, future research can be conducted to investigate domestic guests' perception of capacity management practices using a more representative sample with larger size. Also, further research can be conducted investigate the viewpoint of hotel managers regarding these practices and their impact on domestic guests' perception and loyalty. 


\section{References}

Albert, A.K., \& Augustina, S.S. (2015). Capacity management issues in the hotel industry of Cape Coast Metropolis. Journal of Tourism, Hospitality and Sports, 11(2015), 1-9.

Armistead, C., \& Clark, G. (1993). The "coping" capacity management strategy in services and the influence on quality performance. International Journal of Service Industry Management, 5(2), 5-22.

Baker, S., Huyton, J., \& Bradley, P. (2000). Principles of hotel front office operations. $2^{\text {nd }}$ edition. London: Continuum.

Bolton, L. E., Warlop, L., \& Alba, J. W. (2003). Consumer perceptions of price (un)fairness. Journal of consumer research, 29(4), 474-491.

Bowen, J. T., \& Chen, S. L. (2001). The relationship between customer loyalty and customer satisfaction. International journal of contemporary hospitality management, 13(5), 213-217.

Colliers International (2015) Egypt quarterly review \& forecast. [Online] Available from: http://www.colliers.com/-/media/files/emea/uae/case\%20studies/egypt-marketquarterly-review-english.pdf?la=en-gb. [Accessed: March 21st, 2016].

Creswell, J. (2007). Qualitative inquiry and research design: Choosing among five approaches. $2^{\text {nd }}$ edition. London: Sage Publications Ltd

Cross, R. G., Higbie, J. A., \& Cross, D. Q. (2009). Revenue management's renaissance: A rebirth of the art and science of profitable revenue generation. Cornell Hospitality Quarterly, 50(1), 56-81.

Edgar, D. A. (1997). Capacity management in the short break market. International Journal of Contemporary Hospitality Management, 9(2), 55-59.

Forbes, K.; Berthur, M. and Sebastian, V. (2014). Pricing and domestic tourism performance in Zimbabwe. African Journal of Hospitality, Tourism and Leisure, 3(2), $1-12$.

Gökşen, S. (2011). Implementing revenue management. BMI - paper, Vrije Universiteit Amsterdam. [Online] Available from: http://www.few.vu.nl/en/Images/werkstuk-goksen_tcm244-225780.pdf. [Accessed: April 21 $\left.{ }^{\text {st }}, 2017\right]$.

Jerenashvili, N. (2014). Domestic tourism in Georgia: Quantitative analysis. European Scientific Journal, 2 (special issue) 44-51.

Kimes, S. E. (1994). Perceived fairness of yield management. The Cornell Hotel and Restaurant Administration Quarterly, 35(1), 22-29.

Kimes, S. E. (2003). Revenue management: A retrospective, Cornell Hotel and Restaurant Administration Quarterly, 44 (5/6), 131-138.

Kimes, S. E., \& Wirtz, J. (2003). Has revenue management become acceptable? Findings from an international study on the perceived fairness of rate fences. Journal of Service Research, 6 (2), 125-135.

Kimes, S., \& Anderson, C. K. (2011). Hotel revenue management in an economic downturn. [Online] Available from: Cornell University, School of Hospitality Administration site: http://scholarship.sha.cornell.edu/articles/254. [Accessed: May $\left.15^{\text {th }}, 2017\right]$.

Klassen, K. J., \& Rohleder, T. R. (2001). Combining operations and marketing to manage capacity and demand in services. The Service Industries Journal, 21 (2), 1-30. 
Lee, C., Bergin-Seers, S., Galloway, G., O'Mahony, B. \& McMurray, A. (2008). Seasonality in the Tourism Industry: Impacts and Strategies. Queensland: CRC for Sustainable Tourism Pty Ltd [Online] Available from: http://sustain.pata.org/wpcontent/uploads/2015/02/80085-Lee_TourismIndustSeasonality-WEB.pdf. [Accessed: May $\left.15^{\text {th }}, 2017\right]$.

Malik, F., Yaqoob, S. \& Aslam, A. S. (2012). The impact of price perception, service quality, and brand image on customer loyalty (study of hospitality industry in Pakistan). Interdisciplinary Journal of Contemporary Research in Business, 4(5), 487-505.

Morse, S. C., \& Beckman, E. (2016). A decision model for hotel revenue management displacement analysis for transient room demand vs. group room demand. Journal of Hotel Business and Management, 5 (2), 141-142.

Oh, H., \& Pizam, A. (Eds.). (2008). Handbook of hospitality marketing management. Oxford: Elsevier.

Pallant, J. (2005). SPSS survival manual: A step by step guide to data analysis using SPSS version 12. $2^{\text {nd }}$ edition. Berkshire: Open University Press.

Pan, C.M. (2007). Market demand variations, room capacity, and optimal hotel room rates, International Journal of Hospitality Management, 26 (3), 748-53.

Pierret, F. (2011). Some points on domestic tourism. [Online] Available from: http://www2.unwto.org/agora/some-points-domestic-tourism. [Accessed: May 15 ${ }^{\text {th }}$, 2017].

Pinder, J. (2005). Using revenue management to improve pricing and capacity management in programme management. Journal of the Operational Research Society, 56(1), 75-87.

Pullman, M., \& Rodgers, S. (2010). Capacity management for hospitality and tourism: A review of current approaches. International Journal of Hospitality Management, 29(1), 177-187.

Richard, B. M. (2013). Effect of revenue management practice on customer relationship in 5-star hotels in Nairobi's central business district in Kenya. PhD. Dissertation, Kenyatta University [Online] Available from: http://etdlibrary.ku.ac.ke/handle/123456789/10126. [Accessed: May 15 ${ }^{\text {th }}, 2017$ ].

Sanghavi, P. (2005). Customer perceptions of fairness in hotel revenue management. Unpublished MSc., University of North Texas. [Online] Available from: http://195.130.87.21:8080/dspace/handle/123456789/683. [Accessed: May 15 2017].

Tranter, K. A., Stuart-Hill. T., \& Parker. J. (2009). An introduction to revenue management for the hospitality industry: principles and practice for the real world. New Jersey: Pearson Education Inc.

Tse, T. S., \& Poon, T. Y. (2011). Revenue management: Resolving a revenue optimization paradox. International Journal of Contemporary Hospitality Management, 24(4), 507-521.

Virvilaite, R., Saladiene, V. \& Skindaras, D. (2009). The relationship between price and loyalty in services industry. Engineering Economics, 3, 96-104.

Williams, P., O'Neill, M., \& Ali-Knight, J. (1999). Strategies for managing capacity in Western Australian hotels: An exploratory study. Australian Journal of Hospitality Management, 6(1), 1-1.

Wilson, J. G., Anderson, C. K., \& Kim, S. W. (2006). Optimal booking limits in the presence of strategic consumer behaviour. Online] Available from: Cornell 
University, School of Hospitality Administration site: http://scholarship.sha.cornell.edu/articles/423. [Accessed: May $15^{\text {th }}, 2017$ ].

Wirtz, J., Kimes, S. E., Theng, J. H. P., \& Patterson, P. (2003). Revenue management: Resolving potential customer conflicts. Journal of Revenue and Pricing Management, 2(3), 216-226.

\section{إدرالك النزلاء المحليين لممارسات إدارة الطاقة الإستيعابية فى الفنادق}

\section{الملخص العربي}

تعد الفنادق من المنشآت الإقتصادية الهادفة للربح، و التي دفعتها المنافسة الثديدة فيما بينها إلي إستخدام

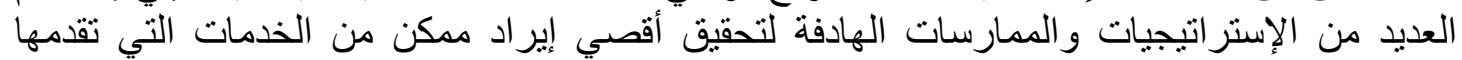

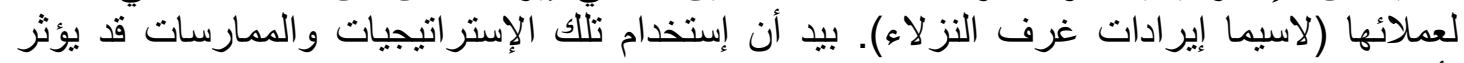

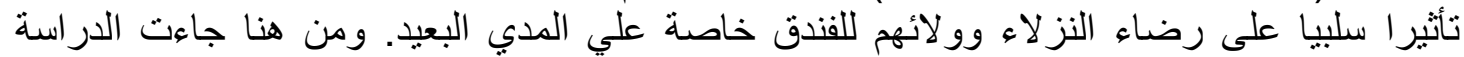

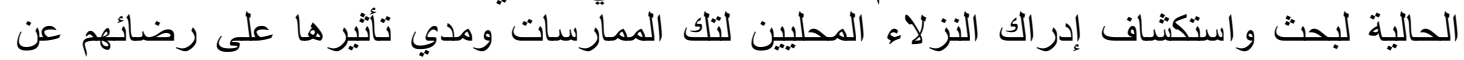

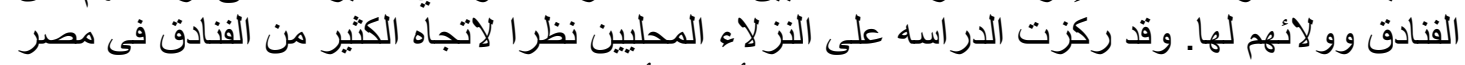

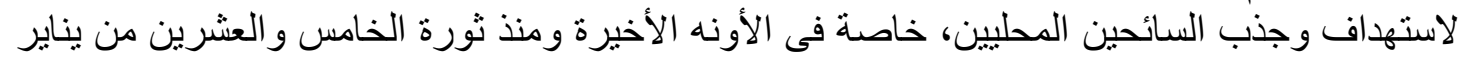

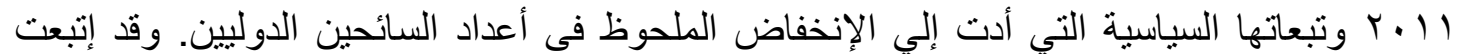

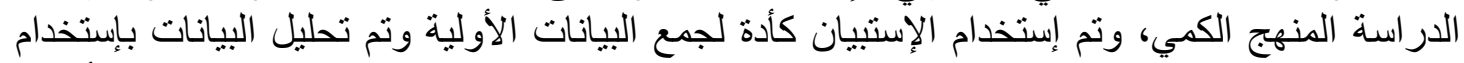

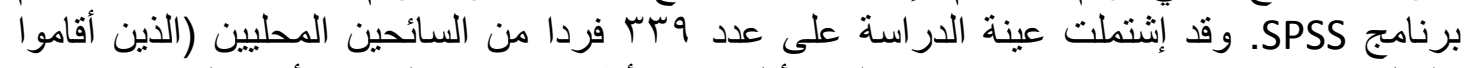

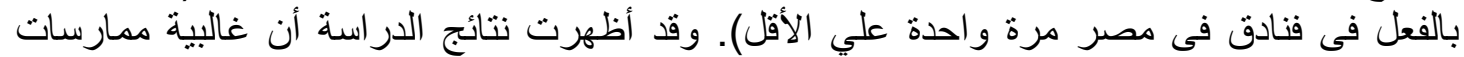

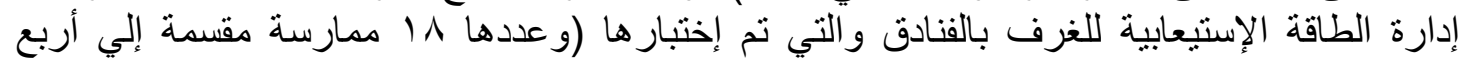

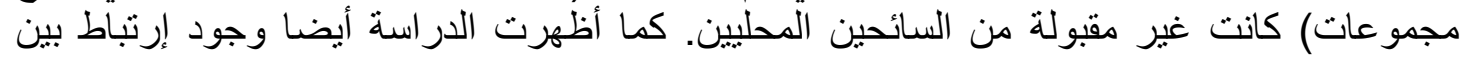

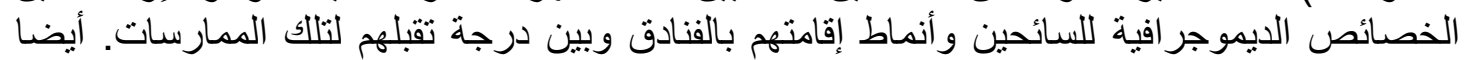

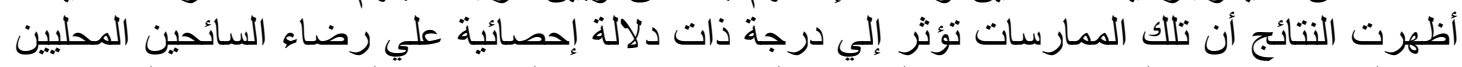

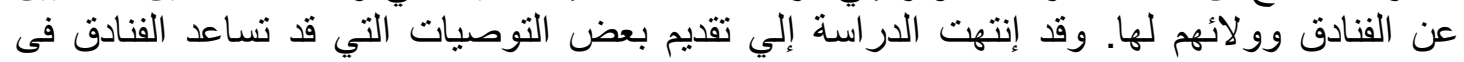

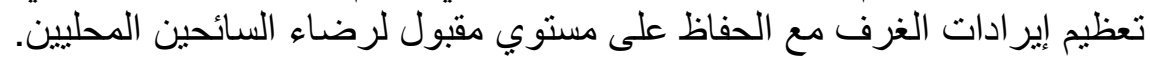

